\title{
Conduction studies along the accessory nerve and follow-up of patients with trapezius palsy
}

\author{
JE PETRERA, W TROJABORG \\ From the Laboratory of Clinical Neurophysiology, Rigshospitalet, University Hospital, Copenhagen, \\ Denmark
}

SUMMARY The accessory nerve was stimulated at the posterior triangle of the neck and responses were evoked simultaneously from the upper, middle and lower part of the trapezius muscle. Sixteen patients were investigated, 10 with trapezius palsy following surgical procedures at the posterior cervical triangle, three with a history suggestive of neuralgic amyotrophy and three of unknown origin. On the unaffected side the latency increases $0.16 \mathrm{~ms}$ per $10 \mathrm{~mm}$ increase in conduction distance corresponding to a conduction velocity of $63 \mathrm{~m} / \mathrm{s}$. Evidence is presented that the upper, middle and lower part of the trapezius muscle receive innervation from the accessory nerve. Follow-up of patients showed spontaneous nerve regeneration after complete axonal degeneration. These findings suggest that surgical intervention should be delayed to allow for spontaneous reinnervation. Clinical recovery was incomplete in cases of iatrogenic origin.

Conduction studies along the accessory nerve were first described 20 years ago by Skorpil and Zverina ${ }^{12}$ who stimulated the nerve at two sites in the posterior triangle of the neck and determined the motor conduction velocity by using the upper part of the trapezius muscle as an indicator. Distal latency to the upper part of the trapezius muscle in normal subjects and patients has later been determined. ${ }^{3-6}$ Electrophysiological studies have also been performed to establish whether or not all parts of the muscle received fibres from the accessory nerve. ${ }^{7}$

The purpose of the present study was to determine normal values of conduction along the accessory nerve by measuring latencies to the upper, middle and lower parts of the trapezius muscle. Case reports are presented to illustrate the usefulness of the method.

\section{Material and methods}

The study included 16 patients, 12 women and four men, 13 to 66 years of age. Ten of them had undergone surgical procedures at the posterior triangle of the neck, in eight due to lymph node biopsy for diagnostic purposes and in two because of a lymphangioma and lipoma respectively. Three patients had a history suggestive of paralytic

Address for reprint requests: J Petrera, MD, Laboratory of Clinical Neurophysiology, Rigshospitalet, Blegdamsvej 9, DK 2100 Copenhagen, Denmark.

Received 16 September 1983. Accepted 2 December 1983 brachial neuritis (neuralgic amyotrophy) and in the remaining three cases the aetiology was uncertain. Most of the patients with lesions related to surgery were investigated bilaterally and the accessory nerve corresponding to the unaffected side was used as control (nine nerves). The accessory nerve was stimulated just above the midpoint of the posterior border of the sternocleidomastoid muscle, where the nerve becomes superficial. ${ }^{8}$ The electrical stimulus, $0.2 \mathrm{~ms}$ in duration, was applied through insulated stainless steel needle electrodes, $0.7 \mathrm{~mm}$ in diameter. The near-nerve electrode, with a bared tip of $3 \mathrm{~mm}$, was adjusted close to the nerve as indicated by the threshold of the muscle action potential $(0 \cdot 5-1 \mathrm{~mA}) .{ }^{9}$ The remote electrode, with a bared tip of $5 \mathrm{~mm}$, was placed $1-1.5 \mathrm{~cm}$ proximal to the near-nerve electrode. The stimulus was delivered from a constant current stimulator (DISA 15 E 07) isolated from ground. The maximal stimulus was at least ten times the threshold. The action potentials were recorded with concentric needle electrodes $\left(0.07 \mathrm{~mm}^{2}\right.$ leading-off area, DISA 13 L 50) from the upper, middle and lower part of the trapezius muscle, adjusting the electrode to obtain a maximal response in each part of the muscle. Bipolar needle electrodes (DISA $13 \mathrm{~K} \mathrm{13)}$ were used when the motor response was contaminated by volume conducted activity from nearby muscles. The motor responses were recorded on a three channel EMG apparatus. The latency was measured from the onset of the stimulus to the onset of the muscle action potential. The distance between the near-nerve stimulating electrode and the recording needle electrode (conduction distance) was measured with an obstetric caliper to the middle and lower part and with a measuring tape to the upper part. Room temperature was $22^{\circ} \mathrm{C}$. 


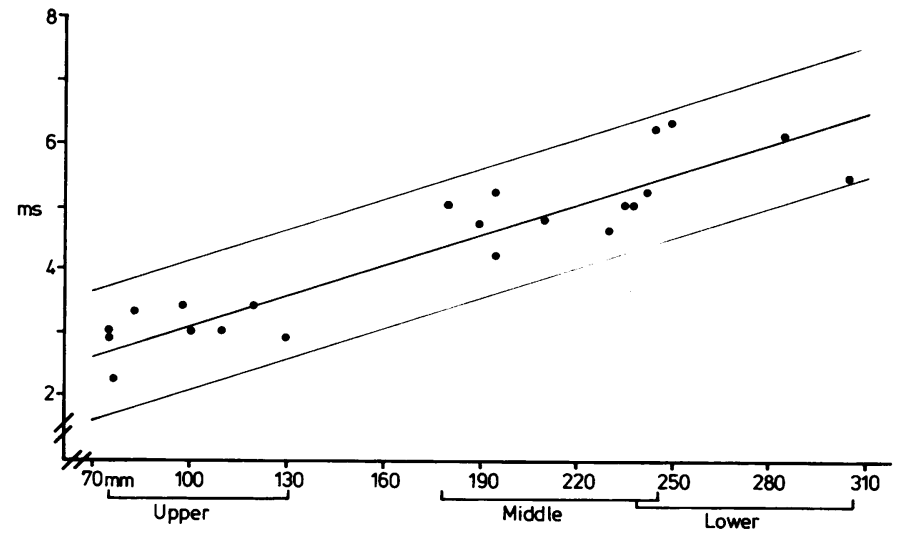

Fig 1 Latency to the upper, middle and lower part of the trapezius muscle as a function of conduction distance. The thick line represents the regression line $(n=22$, $r=0.89)$, the thin lines the $95 \%$ confidence limits.

\section{Results}

In every subject in whom electrodes were placed in the upper, middle and lower part of the trapezius on the unaffected side it was possible to evoke responses from all three sites simultaneously following threshold and maximal stimulation of the accessory nerve. Latencies were determined to the upper part of the muscle in nine subjects, to the middle part in eight and to the lower part in five. The motor latencies ranged from $2 \cdot 2$ to $6 \cdot 3 \mathrm{~ms}$ and the conduction distances from 75 to $305 \mathrm{~mm}$. The latency increased with the distance between the stimulating and recording electrodes (fig 1). A difference in latency of $0.16 \mathrm{~ms}$ per $10 \mathrm{~mm}$ difference in distance corresponded to a conduction velocity of $63 \mathrm{~m} / \mathrm{s}$.

\section{CASE REPORTS}

Among the 10 patients with iatrogenic lesions a typical case was selected to illustrate findings in detail. Case 1 A 43-year-old male who had an enlarged lymph node removed at the posterior triangle of the neck on the right side noticed after the operation limitation of abduction and elevation of the right arm. The right shoulder appeared lower in relation to the left one and there was an aching sensation in the arm, especially after exertion. At the first examination, one month after surgery, there was paralysis of all parts of the trapezius muscle. EMG revealed evidence of total denervation of the upper part of the right trapezius muscle. On the second examination, 3 months later, the force of the upper trapezius muscle was graded as $2^{10}$ while the middle and lower parts were still paralytic. EMG of the upper part showed discrete activity of $1.5 \mathrm{mV}$ amplitude at full effort. There was fibrillation potentials in three sites of the muscle. The latency to the upper part of the trapezius muscle was severely prolonged
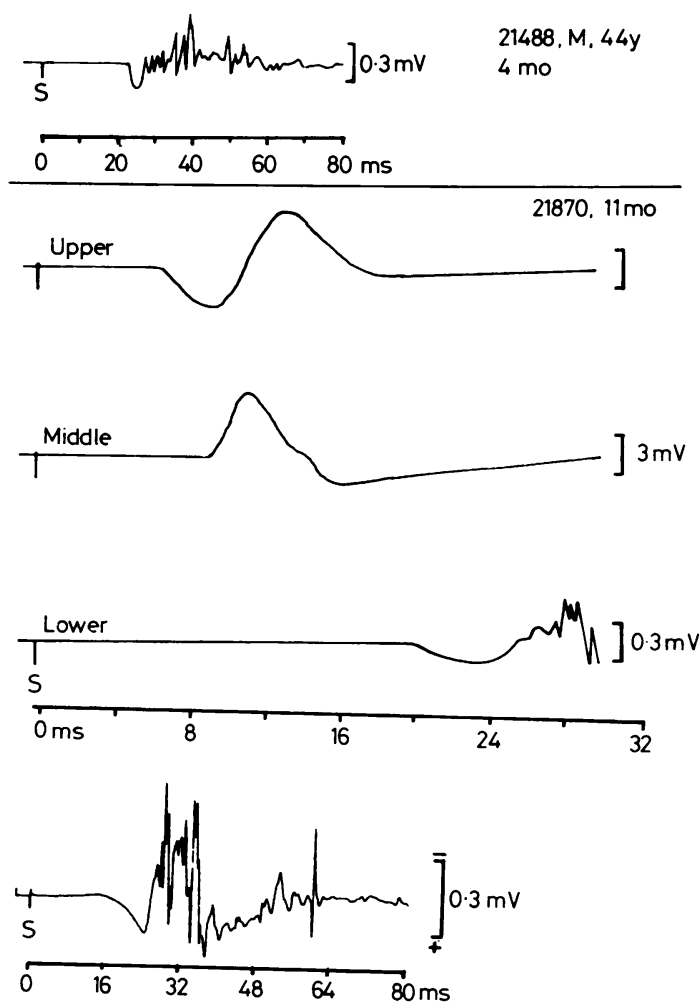

Fig 2 Case 1. Above: response from the upper trapezius muscle recorded by stimulating the right accessory nerve at the posterior triangle of the neck 4 months after nerve injury (latency $23 \mathrm{~ms}$ ); there was no response in the middle and lower parts of the muscle. Middle: responses from all parts of the trapezius muscle, 11 months after nerve injury. Latency to the upper part $6 \mathrm{~ms}$, to the middle part $9 \mathrm{~ms}$ and to the lower part $20 \mathrm{~ms}$. Below: response from the lower part of the muscle, recorded at another time scale. 
( $23 \mathrm{~ms})$, the motor action potential was reduced in amplitude $(0.6 \mathrm{mV})$, polyphasic and of prolonged duration (fig 2). No motor response could be evoked in the mid part. At the third examination, 11 months after the onset of palsy, the force was practically normal in the upper part and grade 3 in the middle and lower part of the trapezius muscle. EMG of the upper and middle part showed reduced recruitment pattern and discrete activity at full effort respectively. There were few fibrillation potentials. In addition there was a $55 \%$ increased mean action potential duration compared with the normal side. The latencies of the evoked responses in the three parts of the right trapezius muscle were prolonged (fig 2), corresponding to conduction velocities of $20-24 \mathrm{~m} / \mathrm{s}$. In the upper and middle part the amplitude was normal, in the lower part the motor response was reduced $(0.7 \mathrm{mV})$, polyphasic in shape and of prolonged duration.

In a similar case, electrophysiological investigation 2 months after nerve injury revealed a complete lesion. On EMG examination 2 months later there were signs of reinnervation in the upper part of the trapezius muscle. Moreover a polyphasic motor response of prolonged duration, reduced amplitude $(0.2 \mathrm{mV})$ and severely prolonged latency $(25 \mathrm{~ms})$, could be evoked by nerve stimulation. The middle and lower parts of the muscle were still totally denervated.

In four other patients with lesions related to surgery there were also prolonged latencies to the upper trapezius muscle ranging from 8 to $35 \mathrm{~ms}$ when investigated 2 to 10 months after onset of palsy (fig 3). When it was possible to evoke responses in the middle and lower part of the muscle, they were conducted at a rate corresponding to about $2-3 \mathrm{~m} / \mathrm{s}$. One year after nerve damage conduction velocity increased to $21-28 \mathrm{~m} / \mathrm{s}$. The findings indicate spontaneous nerve regeneration after Wallerian degeneration in these six cases.

In two other patients latencies were normal and motor responses were slightly reduced in amplitude. Electromyography 8 years after injury was normal in one but indicated loss of motor units with normal amplitude at full effort in the other examined 10 months after nerve damage.

In the remaining two cases electrophysiological investigation 3 months after surgery at the posterior triangle of the neck revealed a complete lesion and nerve repair was performed. In one of them there was electrophysiological evidence of reinnervation corresponding to the upper trapezius muscle 4.5 months after nerve grafting and to all parts of the muscle 11 months after nerve repair. In the other patient signs of reinnervation occurred 9 months after nerve suture.
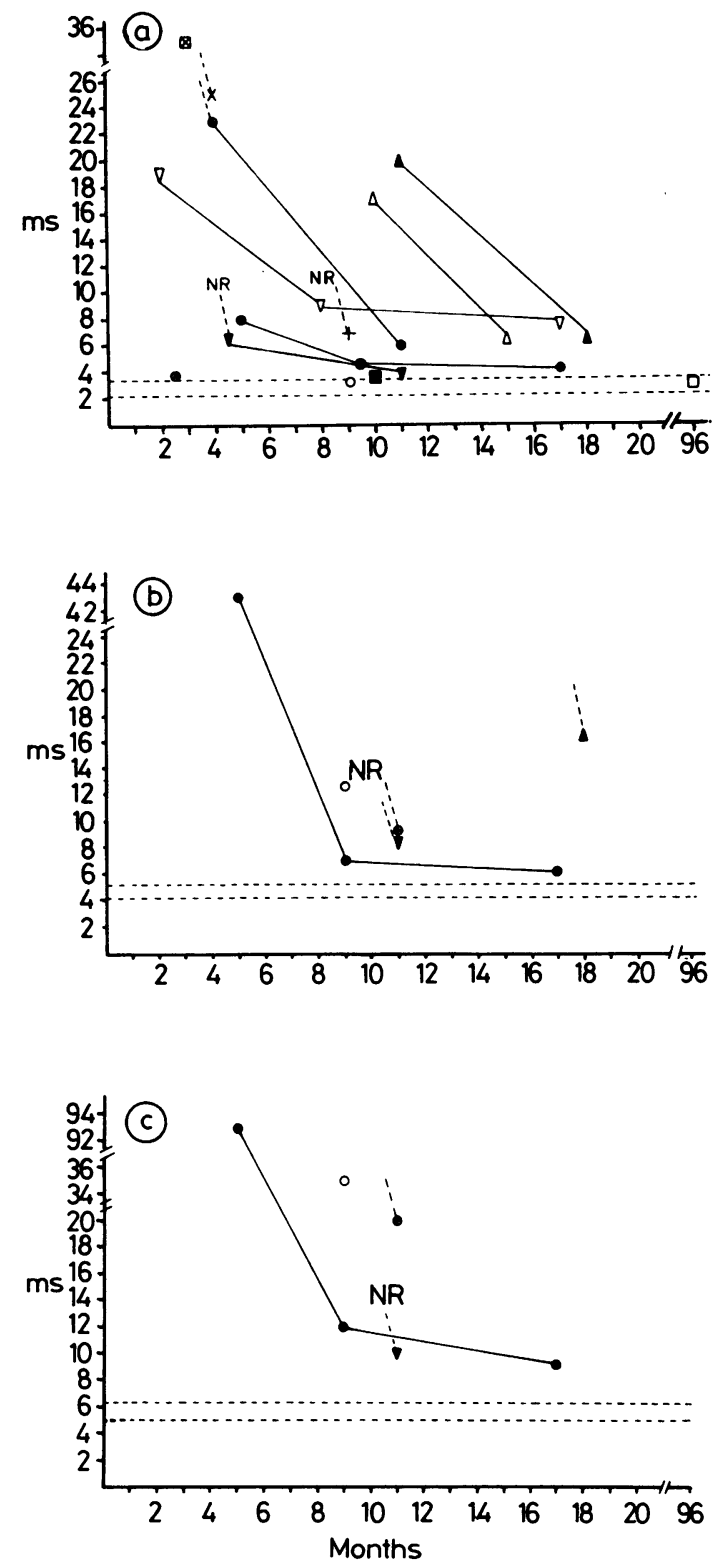

Fig 3 Latencies to the upper $(A)$, middle $(B)$ and lower (C) trapezius muscle in patients with accessory nerve lesion. Each symbol represents one patient $(O, \otimes$ and $\Delta$ are those with a history suggestive of neuralgic amyotrophy, the other ten symbols those with paisies secondary to surgery).

Ordinate: latency in milliseconds. Abscissa: time since nerve injury, nerve repair (NR) or onset of symptoms. The dashed line above a symbol indicates absence of motor responses at a previous investigation. The horizontal stippled lines indicate the range of normal latencies. 
The following case illustrates typical features of patients with a history suggestive of paralytic brachial neuritis (neuralgic amyotrophy).

Case 2 A 28-year-old man woke up in the morning with severe pain in the neck and left shoulder. A few days later he noticed difficulty to abduct the left arm beyond $90^{\circ}$ and to swim. He also noticed sagging of the left shoulder, and the supraclavicular fossa looked deeper on the left side. The pain decreased gradually within a month. During the following 4 or 5 months there was a nearly complete clinical recovery. On examination 9 months after the onset there was normal power of the upper part of the left trapezius muscle, wasting and weakness of the middle and lower parts. In addition there was wasting and slight weakness of the rhomboid muscle. An EMG performed at the time showed signs of chronic partial denervation in the left trapezius and rhomboid muscles. By stimulating the accessory nerve motor responses were recorded in all three parts of the trapezius muscle. The latency to the upper part was normal while it was 2.5 and 5 times increased to the middle and lower part respectively, corresponding to an estimated conduction velocity of 5-9 m/s. The amplitude of the evoked motor response was normal in the upper part, moderately decreased in the middle part and severely decreased in the lower part. The responses were polyphasic in shape and prolonged in duration especially in the lower and middle parts (fig 4).

The electrophysiological findings are consistent with nerve regeneration after complete axonal degeneration. The other two patients also presented neck and/or shoulder pain of 1 to 4 weeks duration and subsequently developed trapezius weakness and wasting; in one case the ipsilateral long thoracic nerve being involved as well. In both, EMG revealed evidence of partial denervation of the trapezius muscle. In one patient the latency to the upper trapezius muscle was at the upper border of normal and the motor response was of reduced amplitude but normal shape; the serratus anterior muscle was totally denervated. In the other patient the latencies to the upper and middle parts were prolonged (fig 3), muscle evoked responses were polyphasic, of reduced amplitude and conduction velocity was estimated to $8 \mathrm{~m} / \mathrm{s}$.

In the remaining three patients the aetiology of the nerve palsy was uncertain. One of them had weakness and wasting confined to the left sternocleidomastoid muscle. Electromyography showed discrete activity of reduced amplitude at full effort but no fibrillation potentials at rest. EMG and conduction along the accessory nerve to all parts of the trapezius muscle were normal.

In five of the 10 patients with iatrogenic lesions,
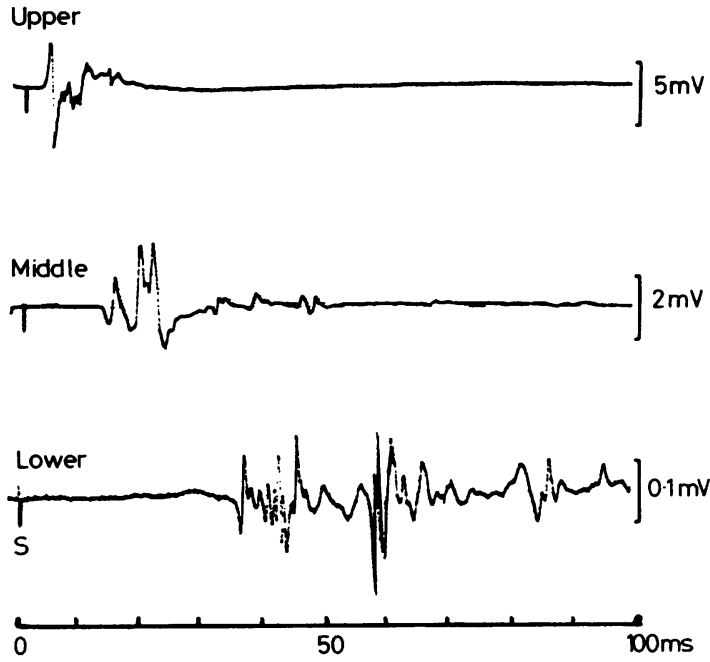

Fig 4 Case 2. Responses from the three parts of the trapezius muscle following stimulation of the left accessory nerve 9 months after onset. Latency to the upper, middle and lower part $3 \cdot 1,12 \cdot 6$, and 35 ms respectively.

there was also damage of the supraclavicular branches of the cervical plexus arising from the third and fourth cervical nerves, as evidenced by dysaesthesia and hypaesthesia for light touch and pinprick in the corresponding territory. One of the patients had also sensory loss in the great auricular nerve distribution.

\section{Discussion}

Stimulation of normal nerves at the posterior triangle of the neck revealed a good correlation between motor latencies and conduction distances. Our findings are in agreement with those of Fahrer et $a l^{7}$ who recorded from all three parts of the trapezius muscle and those of Cherington, ${ }^{3}$ Ramelli et $a l^{4}$ and Krogness 6 who elicited motor responses only from the upper part of the muscle.

The range of motor latencies was similar to that found by stimulating the brachial plexus at Erb's point and recording from the shoulder-girdle and arm muscles."112 Estimate of conduction velocity from the relation between conduction time and distance gave a value of $63 \mathrm{~m} / \mathrm{s}$. That is similar to the mean values found along the proximal segment of the radial nerve ${ }^{13.14}$ and musculocutaneous nerve ${ }^{12}$ and slightly below those found in the accessory nerve by Skorpil and Zverina. ${ }^{2}$

The method proved helpful in establishing the degree of nerve injury due to iatrogenic lesions and in evaluating the degree of nerve recovery. On clini- 
cal and electrophysiological grounds the nerve lesion was diagnosed as complete at the first examination, 1 to $3 \frac{1}{2}$ months after injury, in four patients. Subsequent electromyographic and motor latency studies were consistent with reinnervation after $\mathrm{Wal}-$ lerian degeneration. ${ }^{1516}$ In the other four cases, studied 2 to 5 months after injury, the electrophysiological findings were also consistent with reinnervation after Wallerian degeneration. In fact, there was evidence that spontaneous nerve regrowth occurred in six of eight iatrogenic lesions with total interruption of the axons while the supporting nerve tissue was preserved (axonotmesis) ${ }^{17}$ allowing spontaneous nerve regeneration. The finding suggests that exploration of the nerve in this type of lesion should not be performed before sufficient time has elapsed to allow for spontaneous recovery. In all cases there was electrophysiological evidence of reinnervation, either spontaneously or after nerve repair. However, follow-up of patients 11 months to 8 years after a iatrogenic lesion, revealed incomplete clinical recovery in all.

Accessory nerve lesions during surgical procedures at the posterior cervical triangle have been reported by many authors in the past 50 years. Nerve injury occurred especially due to removal either of tuberculous glands ${ }^{18-23}$ or abnormal masses or lymph nodes for diagnostic purposes..$^{2122-32}$ In these cases the nerve can be severed by the scalpel or by self-retaining retractors or artery forceps to control haemorrhage from the ascending branch of the traverse cervical artery which accompanies the nerve $^{32}$ or by ligature. ${ }^{28}$ The consequences of sacrificing the accessory nerve in radical neck dissection for treatment of neck and head cancer are described in large series. ${ }^{33}{ }^{34}$ Some authors have proposed either to preserve the nerve ${ }^{35}{ }^{36}$ or to repair it at the time of neck dissection ${ }^{28}{ }^{37-39}$ or later. ${ }^{40}$ Nerve suture or grafting was also postulated by several authors as treatment after iatrogenic or open wound damage. 21242628304142 Traumatic closed injuries were reported in relation to accidents, ${ }^{21}$ by using an arm sling ${ }^{43}$ in sports ${ }^{44}$ or due to biting. ${ }^{45} \mathrm{~A}$ case of trapezius palsy following a bee sting has been described.$^{46}$ Cases of accessory nerve damage due to surgery in the anterior triangle of the neck are rare. ${ }^{47}$

In large series of cases of neuralgic amyotrophy isolated accessory nerve palsies have not been reported. ${ }^{48-50}$ Patients with a clinical history similar to our three patients have been described. ${ }^{51152}$ Their palsy was sometimes preceded by neck and shoulder pain of one to several weeks duration, there was variable involvement of the sternocleidomastoid muscle and occasionally of the ipsilateral long thoracic nerve without evidence of a more wide- spread peripheral neuropathy in any of the cases. The diagnosis of neuralgic amyotrophy appears likely in these cases.

It seems that there are many variations in the anatomy of the accessory nerve. During its extracranial course the nerve receives branches from the 2 nd cervical nerve and pierces and innervates the sternocleidomastoid muscle. After entering the posterior cervical triangle at a point slightly above the mid-point of the posterior border of the sternocleidomastoid muscle, it is joined by fibres derived from the 3rd and 4th cervical nerves, forms a sort of plexus beneath the trapezius muscle and supplies this muscle. ${ }^{53}$ It has been suggested that the branches from the cervical nerves are purely afferent. ${ }^{26} 38$

Fahrer ${ }^{7}$ found electrophysiological evidence suggesting that the 3rd and 4th cervical nerves might provide motor fibres to the upper or to all parts of the trapezius muscle. Brodal ${ }^{54}$ states that besides the motor fibres the accessory nerve also contains some afferent fibres and that the cervical nerves only contains sensory fibres, likely to be proprioceptive. Our findings that nerve stimulation at threshold and at maximal strength evoked responses in all parts of the trapezius muscle do not support the assumption of two sources of innervation, that is, the upper one third or one half being supplied by the accessory nerve and the remainder by the 3 rd and 4 th cervical nerves. ${ }^{55}$ It appears unlikely that neighbouring nerves could be stimulated with the small currents used at threshold. On the other hand it cannot be decided from the present study whether in all cases one is actually stimulating the accessory nerve or one of the cervical nerves in cases where the former ends in the sternocleidomastoid muscle. ${ }^{5657}$

\section{References}

' Skorpil V, Zverina E. Conduction velocity in brain nerves in man. Electromyography Louvain Abstracts 1962;2:306.

${ }^{2}$ Skorpil V, Zverina E. The speed of conduction in the cranial nerves in man. Cesk Neurol 1963;26:152-6.

${ }^{3}$ Cherington M. Accessory nerve. Conduction studies. Arch Neurol 1968;18:708-9.

4 Ramelli E, Tralli G, Mapelli G. L'elettromiogramma da eccitamento del nervo accessorio spinale. Acta Neurol (Napoli) 1971;26:100-7.

5 Eisen A, Bertrand G. Isolated accessory nerve palsy of spontaneous origin. Arch Neurol 1972;27:496-502.

- Krogness K. Serial conduction studies of the spinal accessory nerve used as a prognostic tool in a lesion caused by lymph node biopsy. Acta Chir Scand 1974;140:7-11.

${ }^{7}$ Fahrer H, Ludin HP, Mumenthaler M, Neiger M. The innervation of the trapezius muscle. An electrophysiological study. J Neurol 1974;207:183-8. 
${ }^{8}$ Sunderland S. Nerve and Nerve Injuries. 2nd ed. Edinburgh: Livingstone, 1978:1013-4.

9 Trojaborg W, Sindrup EH. Motor and sensory conduction in different segments of the radial nerve in normal subjects. J Neurol Neurosurg Psychiatry 1969;32: 354-9.

${ }^{10}$ Medical Research Council. Aids to the examination of the peripheral nervous system. Memorandum No 45. London: HMSO, 1976.

" Gassel MM. A test of nerve conduction to muscles of the shoulder girdle as an aid in the diagnosis of proximal neurogenic and muscular disease. $J$ Neurol Neurosurg Psychiatry 1964;27:200-5.

12 Trojaborg W. Motor and sensory conduction in the musculocutaneous nerve. J Neurol Neurosurg Psychiatry 1976;39:890-9.

${ }^{13}$ Gassel MM, Diamantopoulos E. Pattern of conduction times in the distribution of the radial nerve. A clinical and electrophysiological study. Neurology (Minneap). 1964;14:222-31.

14 Tönnis D. Untersuchungen über die Leitgeschwindigkeit des N. radialis. Z Orthop 1965;99:497-507.

is Trojaborg W. Prolonged conduction block with axonal degeneration. J Neurol Neurosurg Psychiatry 1977; 40:50-7.

${ }^{16}$ Buchthal F, Kühl V. Nerve conduction, tactile sensibility, and the electromyogram after suture or compression of peripheral nerve: a longitudinal study in man. $J$ Neurol Neurosurg Psychiatry 1979;42:436-51.

${ }^{17}$ Seddon HJ. Three types of nerve injury. Brain 1943;66: 237.

${ }^{18}$ Hanford JM. Surgical excision of tuberculous lymph nodes of the neck. A report on one hundred and thirty-one patients with follow-up results. S Clin North Am 1933;13:301-10.

${ }^{19}$ Wulff HB. The treatment of tuberculous cervical lymphoma: late results in 230 cases treated partly surgically, partly radiologically. Acta Chir Scand 1941; 84:343-66.

${ }^{20}$ Oppikofer EK. Über die grundsätzlich chirurigische Behandlung der Halslymphdrüsen-Tuberkulose. Schweiz Med Wochenschr 1952;82:677-81.

${ }^{21}$ Nordén A. Peripheral nerve injuries to the spinal accessory nerve. Acta Chir Scand 1946;94:515-32.

${ }^{22}$ Mead S. Posterior triangle operations and trapezius paralysis. Arch Surg 1952;64:752-5.

${ }^{23}$ Skonnord O. Über Accessorius-Lähmungen. Dissertation, Zürich, 1957.

${ }^{24}$ Woodhall B. Trapezius paralysis following minor surgical procedures in the posterior cervical triangle. Ann Surg 1952;136:375-80.

${ }^{25}$ Hubault A, Fages A, Kahn MF, deSeze S. Une pseudoperiarthrite de l'épaule. La paralysie du trapeze par lesion chirurgicale du nerf spinal. Sem Hop 1972;48:3029-37.

${ }^{26}$ Seddon H. Surgical Disorders of the Peripheral Nerves. Edinburgh: Churchill Livingstone, 1972:171-4.

${ }^{27}$ Valtonen EJ, Lilius HG. Late sequelae of iatrogenic spinal accessory nerve injury. Acta Chir Scand 1974;140:453-5.

${ }^{28}$ Wright TA. Accessory spinal nerve injury. Clin Orthop 1975;108: $15-18$.
${ }^{29}$ Olarte M, Adams D. Accessory nerve palsy. J Neurol Neurosurg Psychiatry 1977;40:1113-6.

${ }^{30}$ Cherington $\mathbf{M}$, Hendee $\mathbf{R}$, Roland $\mathbf{R}$. Accessory nerve palsy-a painful cranial neuropathy: surgical care. Headache 1978;18:274-5.

${ }^{31}$ Saeed MA, Gatens PF. Accessory nerve palsy-a hazard of lymph node biopsy: case reports. Milit Med 1982;147(7):586-8.

${ }^{32}$ King RJ, Motta G. Iatrogenic spinal accessory nerve palsy. Ann R Coll Surg Engl 1983;65(1):35-7.

${ }^{33}$ Lahey FH. Radical dissection of the neck. S Clin North Am 1949;29:631-40.

${ }^{34}$ Ewing MR, Martin H. Disability following " radical neck dissection". Cancer 1952;5:873-83.

${ }^{35}$ Roy $\mathrm{PH}, \mathrm{Beahrs} \mathrm{OH}$. Spinal accessory nerve in radical neck dissections. Am J Surg 1969;118:800-4.

${ }^{36}$ Stearns MP, Shaheen OH. Preservation of the accessory nerve in block dissection of the neck. $J$ Laryngol Ctol 1981;95(11): 1141-8.

${ }^{37}$ Ballantine AJ, Guinn GA. Reduction of shoulder disability after neck dissection. Am J Surg 1966; 112:662-5.

${ }^{38}$ Anderson R, Flowers RS. Free grafts of the spinal accessory nerve during radical neck dissection. Am J Surg 1968;118: 796-9.

${ }^{39}$ Brandenburg JH, Lee CYS. The eleventh nerve in radical nerve surgery. Laryngoscope 1981;91(11):18519.

${ }^{40}$ Harris HH, Dickey JR. Nerve grafting to restore function of the trapezius muscle after radical neck dissection. Ann Otol 1965;74:880.

${ }^{41}$ Wordhall B. Operative injury to the accessory nerve in the posterior cervical triangle. Arch Surg 1957; 74:122-7.

${ }^{42}$ Trumpy JH. Nervetransplantasjon ved iatrogen skade av nervus accessorius. Tidskr Nor Laegeforen 1977; 12:559-60.

${ }^{43}$ Woodruff $\mathrm{AW}$. Unilateral spinal accessory nerve palsy caused by an arm sling. $\mathrm{Br}$ Med J 1950;1:821.

${ }^{44}$ Bateman JE. Nerve injuries about the shoulder in Sports. J Bone Joint Surg 1967;49-A:785-92.

${ }^{45}$ Paljärvi L, Partanen J. Biting palsy of the accessory nerve.J Neurol Neurosurg Psychiatry 1980;43:744-6.

${ }^{46}$ Risos A. Paresis of the $n$. accessorius following an insect sting. Nervenarzt 1978;49(8):475-9.

${ }^{47}$ Sarala PK. Accessory nerve palsy: an uncommon etiology. Arch Phys Med Rehabil 1982;63:445-6.

${ }^{48}$ Parsonage MJ, Turner JWA. Neuralgic amyotrophy: the shoulder-girdle syndrome. Lancet 1948;1:973-8.

${ }^{49}$ Turner JWA, Parsonage MJ. Neuralgic amyotrophy (paralytic brachial neuritis). Lancet 1957;2:209-12.

${ }^{\text {so }}$ Tsairis P, Dyck PJ, Mulder DW. Natural history of brachial plexus neuropathy. Report of 99 patients. Arch Neurol 1972;27:109-17.

$s^{\prime}$ Spillane JD. Isolated unilateral spinal accessory nerve palsy of obscure origin. $\mathrm{Br}$ Med J 1949;2:365-6.

52 Laha RK, Panchal P. Isolated accessory nerve palsy. South Med J 1979;72(8):1005-7.

${ }^{53}$ Gray H. Anatomy. 15th ed. New York: Bounty Books, 1977:753.

${ }^{54}$ Brodal A. Neurological Anatomy in Relation to Clinical Medicine. 3rd ed. New York, Oxford: Oxford Univer- 
sity Press, 1981:458-9.

${ }^{s 5}$ Haymaker W, Woodhall B. Perpheral Nerve Injuries. Principles of Diagnosis. London: WB Saunders Company, 1953:205.

56 Piersol GA. Human Anatomy. Philadelphia: Lippincott,
1911 (cited by Sunderland S, 1978).

${ }^{57}$ Coleman CC, Walker JC. Technic of anastomosis of the branches of the facial nerve with the spinal accessory for facial paralysis. Am Surg 1950;131:960-8. 